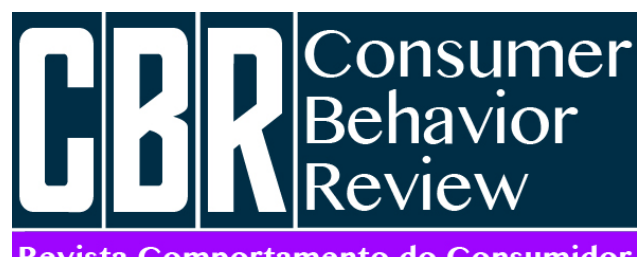

Revista Comportamento do Consumidor
Farias, M. L., Sousa Júnior, J. H., Silva, B. G. F., \& Alcoforado, D. G. (2019). Compreendendo o Domínio "Projetos de Identidade do Consumidor": Revisão de literatura considerando a produção científica brasileira. Consumer Behavior Review, 3(2), 85-98.
ISSN: 2526-7884

Editor: Prof. Dr. Marconi Freitas da Costa E-mail da revista: cbr@ufpe.br
Avaliação: Double blind review

Recebido: 01 de agosto de 2019

Aceito 23 de setembro de 2019

\title{
COMPREENDENDO O DOMÍNIO “PROJETOS DE IDENTIDADE DO CONSUMIDOR": REVISÃO DE LITERATURA CONSIDERANDO A PRODUÇÃO CIENTÍFICA BRASILEIRA
}

\author{
Miriam Leite Farias \\ João Henriques de Sousa Júnior \\ Bianca Gabriely Ferreira Silva \\ Daniela Gomes Alcoforado
}

Miriam Leite Farias é Doutoranda em Administração pela Universidade Federal de Pernambuco - UFPE. E-mail: miriamlfarias@gmail.com João Henriques de Sousa Júnior é Doutorando em Administração pela Universidade Federal de Santa Catarina UFSC. E-mail:

sousajunioreu@hotmail.com. Bianca Gabriely Ferreira Silva é Doutoranda em Administração pela Universidade Federal de Pernambuco UFPE. E-mail:

biianca_ferreira@hotmail.com. Daniela Gomes Alcoforado é Doutoranda em Administração pela Universidade Federal de Pernambuco - UFPE. E-mail: alcoforado.daniela@gmail.com. Esta pesquisa foi financiada pela CAPES Coordenação de Aperfeiçoamento de Pessoal de Nível Superior. Os autores agracedecem aos avaliadores pelos comentários para melhoria do artigo.

\begin{abstract}
Resumo
A Consumer Culture Theory refere-se à um conjunto de perspectivas teóricas que compartilham a mesma orientação sociocultural sobre as relações dinâmicas entre consumidor, mercado e significados culturais. Considerando isso, em 2005, Arnould e Thompson propuseram um framework com quatro domínios temáticos de CCT que são interrelacionados. 0 objetivo deste artigo foi fornecer uma visão geral conceitual dos trabalhos que têm como tema central o domínio "Projetos de Identidade do Consumidor". Para tanto, foi realizada uma revisão de literatura acerca do tema considerando a produção cientifica brasileira de 2005 a 2018. Percebeu-se que os autores brasileiros utilizavam-se da relação pessoa-objeto, principalmente o conceito do self estendido proposto por Belk, além de perspectivas pósmodernas sobre identidades fragmentadas apresentadas por Hall. Portanto, considera-se que a estrutura discursiva dos artigos permaneceu nas teorias e conceitos sobre identidade iniciais ainda difundidos pela publicação de 2005, falhando em alcançar outras propostas mais recentes.
\end{abstract}

Palavras-chave: Identidade, Consumer Culture Theory, Consumo. 


\section{INTRODUÇÃO}

A influência da condição pós-moderna nas ciências sociais trouxe uma nova forma de se pensar e estudar o consumo, questionando o positivismo dominante da área de Consumer Behaviour, na qual a tomada de decisão de compra do consumidor era abordada de maneira economicista e racional. Uma nova corrente se formava incorporando interesses similares de pesquisa que abordassem os aspectos simbólicos do consumo (Levy, 1959). Os debates sobre essa mudança de paradigma começaram na década de 80 com trabalhos inicias explorando, por exemplo, problemáticas como rituais e simbolismo, consumo experiencial e cultura no comportamento do consumidor.

No entanto, essa tradição de pesquisas sobre consumo, delimitada por termos como pósmodernas, interpretativistas, naturalistas, póspositivistas, ou até mesmo relativistas, muitas vezes confundiam ao invés de esclarecer, falhando em trazer semelhanças teóricas. Assim sendo, em 2005, baseados nos trabalhos publicados no Journal of Consumer Research nos vinte anos anteriores, Arnould e Thompson introduziram o label Consumer Culture Theory (CCT) posicionando os trabalhos que fossem orientados para aspectos socioculturais, experienciais, simbólicos e ideológicos do consumo (Arnould \& Thompson, 2005).

A CCT possui uma visão heterogênea de cultura e enfatiza o aspecto produtivo do consumo. Os consumidores são vistos como produtores ao invés de portadores de cultura, construindo e modificando suas expressões pessoais e sociais por meio de significados decodificados de propagandas, marcas e configurações de varejo. Ela emerge de um sistema socioeconômico particular, com o impacto da globalização e do capitalismo. (Arnould \& Thompson, 2005; Arnould \& Thompson, 2007).

Distante de aspirar se tornar um corpo teórico unificado, a CCT refere-se à um conjunto de perspectivas teóricas que compartilham a mesma orientação sociocultural sobre as relações dinâmicas entre consumidor, mercado e significados culturais. Dessa forma, Arnould e Thompson (2005) identificaram quatro domínios centrais de temas referentes às contribuições teóricas para a CCT, são eles:
Projetos de Identidade do Consumidor; Culturas de Mercado; Padrões Sócio-Históricos de Consumo e Ideologias de Mercado; e, Estratégias Interpretativas do Consumidor. Em seu framework, os autores propuseram que essas quatro estruturas eram inter-relacionadas ao invés de forças independentes (Arnould \& Thompson, 2007). Ou seja, um determinado estudo de CCT pode potencialmente apresentar relevância em múltiplos temas.

Dentre os domínios, Projetos de Identidade do Consumidor aparece constantemente, sendo inicialmente uma das temáticas mais trabalhadas nos anos seguintes, possivelmente por ainda se assemelhar à perspectiva dominante do campo de consumer behavior (Gaião, Souza \& Leão, 2012). Em sua ideia inicial, a CCT preocupava-se com os aspectos coprodutivos em que os consumidores construíam seu senso de self a partir de material gerado pelo mercado. Esse mercado era visto como fonte de recursos simbólicos pelos quais os consumidores construíam suas narrativas de identidade (Belk, 1988; Holt, 2002). Os teóricos de CCT voltaram a atenção para a relação entre Projetos de Identidade dos Consumidores e a influência estruturante do mercado, argumentando que o mercado produz certos tipos de padrões de consumo onde os consumidores podem escolher permanecer (Arnould \& Thompson, 2005).

No entanto, mais de uma década se passou desde a publicação de 2005, e os estudos de CCT que antes possuíam um foco individualista, apoiando-se em construtos psicológicos vindos da perspectiva experiencial/humanista herdada da década de 80, na qual se estudava como o fenômeno cultural se torna significante por meio do uso de objetos materiais (Holbrook \& Hirschman, 1982; Belk, 1988), foram sendo transformados pela inserção de novos vernáculos teóricos. Nos anos recentes, por exemplo, a lógica da Assemblege Theory começa a assemelhar-se à temas trazidos em 2005 como bricolagem e co-creation, ambos presumindo que os consumidores poderiam criar os conjuntos de recursos de mercado para alcançar metas de identidades pessoais e coletivas (Arnould \& Thompson, 2015).

Dessa forma, o objetivo deste artigo é trazer clareza sobre a compreensão conceitual existente do domínio Projetos de Identidade proposto por Arnould e Thompson em 2005. 
Para tanto, discute-se como o tema vem sendo abordado teoricamente, considerando o retrato da produção científica brasileira. Ao longo do artigo é fornecido uma visão geral da literatura anterior, trazendo uma base teórica coerente que ajuda a construir o desenvolvimento sobre o tema. Posteriormente, avança-se significativamente, sintetizando as descobertas de pesquisas recentes. E por fim, tenta-se identificar possíveis inspirações para futuras pesquisas.

\section{BASES TEÓRICAS DE PROJETOS DE IDENTIDADE DO CONSUMIDOR E SUAS MARGENS}

A construção da identidade por meio do consumo é um assunto de interesse de pesquisadores de várias áreas de conhecimento, principalmente da Consumer Culture Theory. 0 papel do consumo não se limita à satisfação das necessidades dos consumidores com bens materiais. Os significados sociais e culturais produzidos pelo mercado reforçam o sentido de identidade das pessoas (Levy, 1959; Belk, 1988).

Uma das primeiras tentativas de sintetizar o potencial da influência da identidade para a Consumer Research foi no trabalho de Levy (1959) sobre simbolismo do produto. Ele assume que o consumidor não é orientado pelas funcionalidades dos produtos, mas sim pela percepção de seus significados simbólicos.

Posteriormente, Belk (1988) ofereceu uma nova perspectiva do estudo do self para a Consumer Research. $\mathrm{O}$ autor reuniu uma grande variedade de literatura da antropologia à filosofia, citando exemplos de entrevistas em profundidade, para apoiar a ideia de que os consumidores usam suas posses para ampliar, expandir e fortalecer suas identidades, ele propõe que os bens que possuímos são um dos principais contribuintes e reflexos de nossas identidades.

Por meio desse trabalho, ele trouxe a ideia do self estendido, até então diferente das abordagens anteriores propostas pela tradição de Consumer Behavior, onde tinha-se a finalidade de propor modelos que relacionassem a imagem do consumidor com a imagem do produto ou marca (ver Grubb \& Grathwohl, 1967; Birdwell, 1968). Belk (1988) definiu o self estendido como o sendo a extensão do que o indivíduo é, sumarizando que as mais importantes categorias do Self (o "Eu") são o corpo, processos internos e experiências, e aquelas pessoas, lugares e coisas a que os indivíduos estão ligados. Dessas categorias, as três últimas parecem estar mais claramente estendidas (Belk, 2013).

0 self está relacionado à forma como as pessoas se enxergam, ou seja, à sua identidade; e o self estendido é aquilo que o indivíduo enxerga como seu, estendendo sua identidade aos objetos que possui. A construção do self não é feita de maneira isolada, mas influenciada também por outras pessoas e continuamente transformada ao longo do curso da vida (Belk, 2013). A publicação de Belk (1988) solidificou e acelerou o interesse dos pesquisadores nas formas em como o consumo auxilia a definir a identidade do indivíduo (Ahuvia, 2005). Posteriormente, Belk (2013) atualizou o conceito do self estendido diante das implicações da emergente era digital.

Os objetos são centrais para a definição do self (Ahuvia, 2005; Belk 1988; Tian \& Belk, 2005). 0 foco dado a essa relação pessoa e objeto (posse) iniciado por Belk (1988) prevaleceu em grande parte dos trabalhos de CCT nos anos seguintes. Schouten (1991), por exemplo, abordou as transições de papéis e identidades no contexto de cirurgias plásticas. Tian e Belk (2005) estudaram os significados dos bens exibidos nos escritórios dos funcionários em uma empresa de alta tecnologia e sugeriram extensões para o conceito do self estendido. Price, Arnould e Curasi (2000) também utilizam o conceito do self estendido e abordaram a perda de identidade por meio da disposição da posse, realizando um estudo com consumidores idosos.

Em outro desdobramento do conceito, Morgan (1993) promoveu uma ampliação da ideia do self explorando uma dimensão adicional, sob a forma de possíveis selves (Eus). Nesta dimensão, os possíveis selves são constituídos por representações do self em experiências do passado, atividades presentes e representações imaginárias futuras. Eles refletem o que os consumidores podem se tornar, o que eles gostariam de se tornar, e ainda, o que eles tem medo de se tornar (Markus \& Narius, 1986).

Reforçando esta proposta de transição no tempo, Ahuvia (2005) aponta a composição 
narrativa como forma de enxergar o self. 0 autor sugere que os atributos que compõem as identidades estão ligados a eventos na vida do consumidor, que quando acionados podem formar uma história. Ele investiga as formas como posses e atividades que os consumidores adoram, ajudam a resolver conflitos na narrativa identitária. Ahuvia (2005) também destaca que o sentimento de múltiplas identidades e de fragmentação que sente o consumidor contemporâneo, ascende no discurso de pesquisadores pós-modernos que colocam como condições da pós-modernidade experiências de consumo múltiplas e desconexas, e que o sujeito possui o self fragmentado.

O tema Projetos de Identidade do Consumidor ainda pode ser verificado em como os consumidores são constituídos pelos ideais de mercado promulgados nos discursos do capitalismo corporativo global (Belk et al., 2003), e ainda, no contexto de experiências dos consumidores, como é o caso do trabalho de Joy e Sherry Jr. (2003) que focaram na experiência somática não apenas o processo de pensar fisicamente mas como o corpo informa a lógica do pensamento sobre a arte. Tais autores examinaram ligações entre incorporação, movimento e experiência multissensorial, na medida em que ajudaram a elucidar os contornos da apreciação da arte em um museu.

Uma vez apresentadas as principais bases conceituais que fundamentam o domínio Projetos de Identidade sob uma orientação sociocultural, o próximo capítulo deste estudo destaca alguns trabalhos pontuais relacionados ao tema nos últimos anos, possibilitando, dessa forma, um aprofundamento maior na concepção teórica apresentada no campo científico.

\section{ESTUDOS RECENTES SOBRE PROJETOS DE IDENTIDADE DO CONSUMIDOR}

Em 2007, Arnould e Thompson tentaram estender os debates teóricos e institucionais levantados sobre o artigo de 2005. Os quatro domínios de interesse teórico são generosos e podem ser aplicados de uma forma muito flexível que deve ser capaz de abranger um amplo espectro de questões teóricas e preocupações. A chave para essa flexibilidade é que isso estrutura de mapeamento não é voltada para qualquer lista específica de preocupações atuais ou orientações metodológicas (Arnould \& Thompson, 2007). Os autores enfatizam a interrelação entre os domínios, eles são flexiveis e os temas dialogam entre si. Dessa forma, propuseram que o domínio Projetos de Identidade do Consumidor era basicamente fundamentado em estudos sobre Jogos de identidade, imagem e representação do eu; diversidades entre os gêneros; distinções simbólicas; self estendido; contradições culturais e dimensões experienciais do consumo.

A utilização do conceito de self, da construção da identidade por meio da posse, apesar de ter diminuído com o passar dos anos, ainda é um aporte teórico recorrente ao se estudar identidade e consumo. Venkatesh, Joy, Sherry e Deschenes (2010), por exemplo, investigaram os links entre a estética da moda de luxo, do corpo e da formação identitária. Chen e Nelson (2017) utilizam o conceito de "new poors" para exemplificar consumidores que possuem uma identidade ambígua e fragmentada ao terem práticas de consumo que não condizem com sua segmentação por renda.

Com relação à identidade coletiva, Epp e Price (2009) revelam como famílias utilizam formas de comunicação e usam os recursos do mercado para gerenciar interações entre identidades individuais, relacionais e coletivas. Estes autores ainda mostraram como objetos da casa se tornam recurso para a construção dessas identidades. Ainda sobre esse aspecto de coletividade, Weijo, Mertin e Arnould (2018) questionaram como movimentos de consumidores organizados coletivamente se mobilizam para transformar o mercado.

Bahl e Milne (2009) analisam a identidade de um ponto de vista pós-moderno. Os autores sustentam que deve-se considerar a experiência do consumidor através não apenas de um self, mas da interação de múltiplos selves. Os pesquisadores examinaram múltiplos selves especialmente quando estão em conflito. Patterson e Schroeder (2013) também utilizam essa lógica para realizar uma análise de tatuagens na pele questionando a compreensão dominante de projetos de identidade da CCT, a qual, segundo aos autores, teria uma atenção voltada para o individual.

Por fim, os aspectos sensoriais e experienciais do consumo também são implícitos à questão da identidade do 
consumidor. Alguns pesquisadores explorararam a construção da experiência de consumo em espaços liminais como como festivais (Kozinets, 2002). Tumbat e Belk (2011) realizaram um estudo etnográfico sobre as expedições de escalada comercializadas no Monte Everest, os autores forneceram evidências significativas de que os participantes da pesquisa negociam e gerenciam várias tensões do mercado dentro uma ideologia de desempenho individual. Também por meio de uma etnografia da cultura do surf, Canniford e Shankar (2013) teorizam as experiências de natureza dos consumidores como emergentes de assembleges de recursos heterogêneos. Uma teoria de assemblage mostra que as geografias materiais são vitais para a reprodução de discursos românticos.

Além desses subtemas dentro do domínio, Arnould e Thompson (2007) acharam necessário elaborar conexões holísticas que facilitassem o diálogo entre os quatro temas de interesse comuns do framework original. Projetos de Identidade do Consumidor faz link com Padrões Sócio-Históricos de Consumo por meio de "tensões estruturais", assim como, Ideologias de Mercado massivamente mediadas e Estratégias Interpretativas dos Consumidores faz link com ele por meio de "Formas Ideológicas de Identidade dos Consumidores". A Figura 1 sintetiza essa proposta de quadro conceitual dos autores.

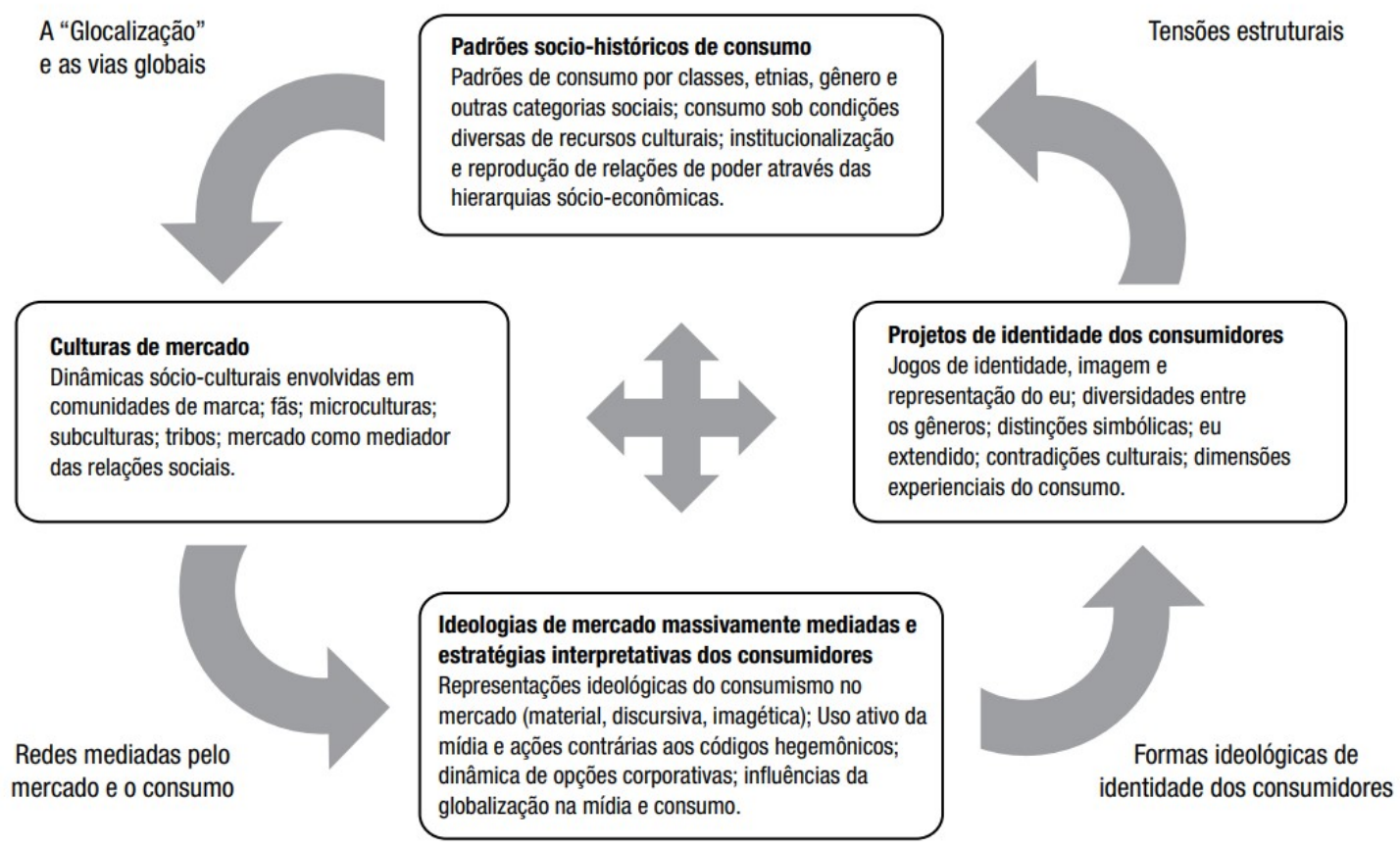

Fonte: Gaião, Souza e Leão (2012)

Figura 1: Framework sintetizado da CCT

Como mostra a Figura 1, a relação intersticial de "tensões estruturais" se localiza entre Projetos de Identidade do Consumidor e Padrões Sócio-Históricos de Consumo, ela refere-se à questões de reprodução social e transformção da identidade. Alguns dos estudos nessa perspectiva destacam a criação de novas identidades híbridas, que têm que lidar com vestígios de hierarquias social e racial (Kates, 2002), outros destacam as formas que os esforços conscientes dos consumidores para atingir a mobilidade ascendente e reconstruir suas identidades quando estas são sutilmente prejudicadas por estratificações sociais de classe e gênero (Üstüner \& Holt, 2007). Por exemplo, Jafari e Goulding (2008) investigaram pessoas refugiadas que reconstruíram suas identidades ao se deslocarem para viver em lugares com idiomas e costumes diferentes.

Quanto à inserção da conexão "Formas Ideológicas de Identidades dos Consumidores", esta sugere que ao invés da dicotomia agência e estrutura, onde muitas vezes ocorre uma dominância, os estudos de CCT têm interrogado 
uma dinâmica mais complexa, onde consumidores exercem uma ação e buscam metas de identidades através de um diálogo (prático e narrativo) com os quadros culturais que são impostos por ideologias dominantes. A agência seria muitas vezes contingente entre sistemas ideológicos concorrentes e discursos de poder. Para Goulding e Saren (2009, p. 27), lugares onde o mainstream é contestado, novas identidades são construídas e performadas. Seguindo essa linha, Cronin, McCarthy \& Collins (2014) destacam que os consumidores têm a capacidade de cooperar para desafiar certas regras sociais, contrapor-se às normas e gostos orientados pelo mercado e estabelecer suas próprias escolhas de consumo, processos e práticas.

Por fim, Projetos de Identidade do Consumidor também têm ligação com o domínio Culturas de Mercado. Aqui os consumidores são vistos como produtores de cultura, ao invés de meramente portadores de cultura. É relevante investigar como os consumidores constroem um senso de identidade coletiva ou comunidade de consumo e como eles compartilham valores comuns em relação ao mercado (Arnould \& Thompson, 2005). Exemplos de contribuições que se enfatizam essa relação podem ser encontrados nos trabalhos que tratam sobre fandom (Smith, Fischer \& Cole, 2007) e consumer tribes (Cova, Kozinets \& Shankar, 2012).

\section{O MÉTODO: DESK RESEARCH}

0 procedimento metodológico adotado neste estudo foi a desk research. De acordo com Macias-Chapula (1998, p. 134), a revisão bibliométrica, como também é conhecida, é caracterizada pelo "estudo dos aspectos quantitativos da produção, disseminação e uso da informação registrada [...] que desenvolve padrões e modelos matemáticos para medir esses processos, usando seus resultados para elaborar previsões e apoiar tomadas de decisão". Para a seleção dos dados que seriam analisados, procedeu-se a construção de um corpus de pesquisa composto por artigos que tratassem do tema identidade do consumidor dentro de uma perspectiva sociocultural. A busca dos artigos efetuou-se pela base de dados Spell a partir do ano de 2005, data que representa a publicação do artigo de Arnould e Thompson no Journal of Consumer Research. Para análise dos dados, utilizou-se a análise documental, que funciona como uma análise de conteúdo dos documentos selecionados que fazem parte do corpus (Pimentel, 2001).

Definida a base de dados, buscou-se o termo "identidade" em artigos científicos de idioma português abrangendo a área de conhecimento de Administração. 0 termo foi buscado nos resumos dos artigos, também fora determinado um período de publicação de 2005 a 2018. Ao total foram encontrados 419 artigos que continham o termo identidade presente em seus resumos. A Tabela 1 expõe a distribuição da quantidade de artigos encontrados pelo ano de publicação nessa primeira fase de busca.

Tabela 1

Distribuição de Artigos Publicados/Ano de publicação \begin{tabular}{l|l} 
Ano de Publicação & Quantidade de Artigos
\end{tabular}

\begin{tabular}{l|l}
2005 & 11 \\
2006 & 11 \\
2007 & 20 \\
2008 & 17 \\
2009 & 22 \\
2010 & 28 \\
2011 & 31 \\
2012 & 25 \\
2013 & 47 \\
2014 & 34 \\
2015 & 44 \\
2016 & 40
\end{tabular}




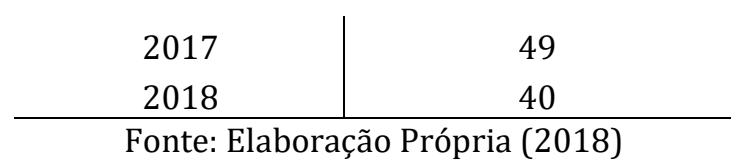

Conforme pode ser observado na Tabela 1 , a quantidade de publicações no contexto brasileiro sobre identidade vem crescendo nos últimos treze anos, desde 2005. No entanto, vale salientar que esses artigos envolvem diversas áreas de pesquisa de Administração, incluindo também perspectivas positivistas sobre identidade. Dessa forma, considerando que o objetivo desse trabalho é analisar como está sendo trabalhado conceitualmente o domínio Projetos de Identidade do Consumidor proposto por Arnould e Thompson (2005), o corpus desta pesquisa passou por um processo de refinamento de quatro etapas, reduzindo o número de artigos de 419 para 34.

Realizada a primeira busca sobre o termo identidade foram encontrados um total de 419 artigos de diversas áreas científicas, dessa forma, a primeira etapa do processo foi excluir os artigos que não faziam parte da área de marketing. Restaram então 87 artigos. Ainda, esse estudo se concentra em uma tradição específica da área, que considera os aspectos socioculturais e ideológicos do consumo. Assim sendo, a segunda etapa consistiu em excluir os artigos que tivessem posicionamentos contraditórios à Consumer Culture Theory, totalizando 50 artigos no final. Após restarem apenas os estudos que teriam alguma característica de CCT, a terceira etapa excluiu os artigos que não faziam uso conceitual do termo identidade, trazendo-o de forma banalizada no texto. Por fim, a quarta e última etapa do processo de filtragem, excluiu os artigos que abordassem a temática identidade de marca, tendo em vista que o que pretendemos discutir de alguma forma é a construção da identidade do consumidor. Esse processo de refinamento reduziu o corpus de pesquisa de 419 para 34 artigos. A Tabela 2 expõe as etapas e a quantidade de artigos excluídos correspondentes a cada uma.

Tabela 2

Etapas e quantidade de artigos excluídos

\begin{tabular}{c|c|c|c}
\hline $\begin{array}{c}\text { Etapas processo de } \\
\text { Filtragem }\end{array}$ & Caracterização da Etapa & $\begin{array}{c}\text { Qtd. de } \\
\text { artigos } \\
\text { excluídos }\end{array}$ & $\begin{array}{c}\text { Corpus } \\
\text { restante }\end{array}$ \\
\hline Primeira Etapa & Artigos de áreas distintas do marketing & 332 & 87 \\
\hline Segunda Etapa & Artigos que não condizem com a CCT & 37 & 50 \\
\hline Terceira Etapa & Uso não conceitual do termo identidade & 8 & 42 \\
\hline Quarta Etapa & Artigos que abordaram identidade de \\
marca & 8 & 34 \\
\hline
\end{tabular}

Fonte: Elaboração Própria (2018)

Em suma, na primeira busca pelo termo na base de dados Spell, obteve-se um total de 419 artigos de diversas áreas. Como exposto na Tabela 2, na primeira etapa de refinamento foram excluídos 332 artigos que não eram da área de marketing, deixando um corpus total de 87 artigos. Dos quais 37 foram excluídos na segunda etapa por não apresentar uma perspectiva de CCT, restando no total 50 artigos para o corpus de pesquisa. Ainda, na terceira etapa de refinamento, desses 50 foram excluídos 08 artigos que não apresentavam o uso conceitual da palavra identidade. E, por fim, na quarta etapa, 08 artigos foram excluídos por tratarem da temática identidade de marca e não de identidade do consumidor. No corpus total de análise constaram 34 artigos que serão discutidos adiante.

Como podem ser observados pela Tabela 3 , os 34 artigos foram encontrados em 19 periódicos distintos de classificação B5 a A2 segundo o quadriênio 2013-2016 da CAPES (Coordenação de Aperfeiçoamento de Pessoal de Nível Superior). 0 fato de ter-se detectado 19 periódicos diferentes para as 34 publicações mostra que não há uma tendência de publicação da temática de identidade em um periódico específico. Os periódicos que mais se destacaram na quantidade de publicações estão descritos abaixo. 
Compreendendo o Domínio "Projetos de Identidade do Consumidor": Revisão de literatura considerando a produção científica brasileira

Tabela 3

Quantidade de Publicações sobre Identidade, por Periódico

\begin{tabular}{lcc}
\multicolumn{1}{c}{ Periódico } & Qualis & Quant. \\
Revista Brasileira de Marketing - ReMark & B1 & 7 \\
Cadernos Ebape & A2 & 3 \\
Pensamento \& Realidade & B3 & 2 \\
Pensamento Contemporâneo em & B2 & 2 \\
Administração & B4 & 2 \\
Revista Interdisciplinar de Marketing - RIMAR & B1 & 2 \\
Revista de Ciências da Administração - RCA & A2 & 2 \\
Rausp & B2 & 2 \\
Organizações em contexto & B2 & 2 \\
Revista ADM.MADE & B1 & 1 \\
Revista de Negócios & B3 & 1 \\
Revista de Administração Imed & B2 & 1 \\
Revista Pretexto & B2 & 1 \\
Revista Gestão Organizacional & B3 & 1 \\
AOS - Amazônia, Organizações e & B2 \\
Sustentabilidade & B3 \\
Revista Alcance & B1 \\
PODIUM Sport, Leisure and Tourism Review & B5 \\
Revista Eletrônica de Administração - Read & A2 & 1 \\
Marketing \& Tourism Review & & 1 \\
Revista de Administração de Empresas - RAE & &
\end{tabular}

Conforme exposto, percebe-se que onze dos dezenove periódicos que mais publicaram sobre o tema são de nível B1, sendo a "Revista Brasileira de Marketing - ReMark" o com maior quantidade de artigos publicados na área de Consumer Culture de 2005 a 2018.

\section{RESULTADOS: BASE CONCEITUAIS REVISADAS}

Por fim, esta análise se concentrou nos conceitos de identidade utilizados pelos autores

do corpus de pesquisa. Por meio de uma análise de conteúdo documental foi possível identificar cinco principais conceitos sobre identidade. Vale salientar que o intuito desta revisão se baseia na forma como os autores dos artigos que analisados aqui fizeram uso dos conceitos, não sendo dessa forma um estado da arte. 0 Quadro 1 apresenta a denominação dos conceitos, sua definição de forma geral e os autores mais utilizados para embasá-los.

\begin{tabular}{|c|c|c|}
\hline Conceitos de identidade & Definição & Autores mais utilizados \\
\hline Fragmentação da identidade & $\begin{array}{c}\text { O sujeito pós-moderno assume } \\
\text { identidades diferentes em } \\
\text { diferentes momentos, identidades } \\
\text { que não são unificadas ao redor de } \\
\text { um 'eu' coerente" }\end{array}$ & $\begin{array}{c}\text { Hall (2006); Baudrillard } \\
\text { (2007) }\end{array}$ \\
\hline
\end{tabular}




\begin{tabular}{|c|c|c|}
\hline Significado dos bens & $\begin{array}{c}\text { Por meio dos significados dos bens } \\
\text { os consumidores criam e sustentam } \\
\text { estilos de vida, constroem noções } \\
\text { de si e definem-se coletivamente, } \\
\text { tornando o consumo responsável } \\
\text { pela estruturação da realidade e do } \\
\text { contexto cultural }\end{array}$ & McCracken (2003) \\
\hline Extensão da identidade & $\begin{array}{c}\text { As posses representam partes da } \\
\text { extensão do self do consumidor, } \\
\text { envolvem a criação, o aumento e a } \\
\text { preservação do senso de identidade }\end{array}$ & Belk (1988); Belk (2013) \\
\hline Identidade do grupo & $\begin{array}{c}\text { Práticas de consumo podem revelar } \\
\text { identidades estigmatizadas para as } \\
\text { outras pessoas }\end{array}$ & Baumann (2003) \\
\hline Noção de diferença & $\begin{array}{c}\text { A identidade é relacional: o que } \\
\text { define o que somos também está } \\
\text { em algo além do nosso ser; o que } \\
\text { não somos também nos define }\end{array}$ & Woodward (2009) \\
\hline
\end{tabular}

Fonte: Elaboração própria (2018)

Quadro1: Síntese dos conceitos de identidade analisados

\section{Fragmentação da identidade}

Nos textos que utilizam o conceito de fragmentação da identidade, a base teórica utilizada é a condição pós-moderna. Segundo Hall (2006, p. 7), a crise de identidade que se apresenta na contemporaneidade é parte de "um processo mais amplo de mudança, que está deslocando as estruturas e processos centrais das sociedades modernas e abalando os quadros de referência que davam aos indivíduos ancoragem estável no mundo social". O sujeito pós-moderno não possui identidade única e fixa, mas sim várias identidades coexistentes.

Neste contexto, como observa Barbosa (2010), a identidade subjetiva dos indivíduos ficou abalada, na medida que vários segmentos culturais - como gênero, sexualidade e etnia, por exemplo - também foram modificados, implicando um deslocamento e uma descentralização dos indivíduos em relação aos seus lugares nas esferas social e cultural do mundo.

\section{Significado dos bens}

0 entendimento da cultura de consumo além da materialidade dos bens passa também pela compreensão da sociedade, uma vez que esta prática se debruça pelas representações simbólicas de poder e identidade do indivíduo (Belk, 1988, Miller, 2007) em meio a diversas proposições de estilos de vida. Os consumidores são compreendidos como produtores culturais, escolhendo práticas de consumo que estejam aliadas à sua própria identidade, além de se adequar a modelos de identidade dominantes determinados pelo mercado (Belk, 1988; Gaião, Souza \& Leão 2012).

Dessa forma, para McCracken (2003), os consumidores utilizam os significados simbólicos dos bens de consumo para desenvolver e sustentar estilos de vida e construir noções de si de forma individual e coletiva, tornando o consumo o principal responsável pela realidade construída culturalmente.

\section{Extensão da identidade}

O conceito do "Self estendido" de uma pessoa tem relação com a posse de determinados bens refletidos na sua identidade. Os bens são os principais responsáveis pelos reflexos da identidade do consumidor. Para Belk (1988), essa extensão inclui além de objetos, lugares, outras pessoas e as partes do corpo do indivíduo. A inovação trazida por este conceito subtende um relacionamento até então diferente entre os consumidores e as marcas de produtos, contribuindo, assim, para o entendimento de que você é o que você possui, as posses serviriam como forma de estender faces identitárias relevantes do indivíduo.

Em meio à consolidação da esfera digital, em 2013, Belk atualiza seu conceito e argumenta que na Internet o "Self estendido" manifesta-se de forma diferente. Para o autor, o indivíduo 
com um perfil em mídias sociais está experimentando o "core" da extensão do seu "Eu" no mundo digital. Ao participar das mídias sociais o consumidor poder desenvolver uma percepção mais ampla do seu self estendido digitalmente, levando a compreensão de que espaços virtuais funcionam com uma parte de cada um. As redes sociais, como por exemplo o Facebook, são uma espécie de auto apresentação para os seres humanos (Belk, 2013).

\section{Identidade do grupo}

0 processo de consumo faz parte da própria identidade dos membros de um grupo como um todo (Helal et al., 2010), considerando a importância do valor simbólico dos bens para os integrantes das tribos. Para Rocha e Barros (2004), o simples ato de consumir se representa um fato social que pode gerar não só representações individuais, mas representações coletivas

0 valor de um objeto pode refletir na forma que o mesmo produto passa a ter significados diferentes para cada tribo distinta (Cova, 1997). Assim, como argumentam, Barboza e Silva (2012) apenas os membros da mesma tribo são capazes de compreender os significados de cada produto na construção de uma identidade grupal.

\section{Noção de diferença}

Por fim, o último principal conceito de identidade que fora achado em nossa análise diz respeito à noção de diferença de Woodward (2009). A autora traz o entendimento que a identidade é algo relacional: o que não somos também nos define. É a ideia de identidade pela diferença, que, por meio da primeira delimitação identitária, buscam-se sistemas classificatórios que estabelecem diferenças sociais e simbólicas entre indivíduos em relações sociais.

Por meio da construção do social e do simbólico, os consumidores compartilham características identitárias e, dessa forma, formam grupos, aceitando-se como similares e negando os que são diferentes. São construídos processos de significação. Corroborando com Woodward (2009), Silva (2009) afirma que a identidade e a diferença são constantemente criadas e recriadas pelo contexto cultural. Para o autor, "a identidade e a diferença têm a ver com a atribuição de sentido ao mundo social e com disputa e em torno dessa atribuição" (Silva, 2009, p. 96).

\section{CONSIDERAÇÕES FINAIS}

A Consumer Culture Theory refere-se a um conjunto de perspectivas teóricas que compartilham a mesma orientação sociocultural sobre as relações dinâmicas entre consumidor, mercado e significados culturais (Arnould \& Thompson, 2005). Arnould e Thompson (2005) propuseram o label CCT inicialmente para tentar desmistificar alguns equívocos sobre a tradição de pesquisa culturalista sobre consumo, principalmente em relação ao uso de métodos qualitativos, dos achados serem dependentes do contexto, e da falta de relevância prática. Em segundo lugar, os autores queriam orientar melhor os pesquisadores que trabalhassem sob essa orientação, para tanto, construíram um framework com quatro domínios temáticos que são inter-relacionados.

Com o tempo, as contribuições do artigo original tornaram a CTT uma comunidade acadêmica legítima (Arnould \& Thompson, 2007; 2015). A CCT não é apenas um label ou uma marca para promover as pesquisas interpretativistas do consumidor, ela constitui uma comunidade de conhecimento, deixando as margens da Consumer Research, alcançando sua legitimidade ao ter lugar em Journals consagrados da área, como o Journal of Consumer Research, departamentos e programas de Universidades, assim como, na prática gerencial do marketing.

Casotti e Suarez (2016) afirmam, que, nos últimos anos, o campo buscou teorizar a respeito das conexões entre ideologias políticas, estruturas de mercado e relações de poder nas dinâmicas de consumo. 0 foco dos trabalhos iniciais que pareciam evocar uma herança da perspectiva do comportamento do consumidor, propensos a olhar prioritariamente para o indivíduo (Gaião, Souza \& Leão, 2012), atualmente voltam-se para dinâmicas de mercados, buscando entender como elas se formam, se legitimam e se transformam (Casotti \& Suarez, 2016). Dessa forma, o objetivo deste artigo foi fornecer uma visão geral dos trabalhos que têm como tema o domínio Projetos de Identidade do Consumidor, 
buscando identificar principais conceitos utilizados para embasar o tema. Para delimitar esse retrato, foi realizada uma revisão de literatura considerando a produção científica brasileira de 2005 a 2018. Dessa forma, foi possível construir um corpus de pesquisa composto por artigos que tratassem do tema identidade do consumidor dentro de uma perspectiva sociocultural.

Durante a análise dos artigos selecionados foram identificados cinco principais conceitos: Fragmentação da identidade; Significados dos bens; Extensão da identidade; Identidade de grupo; e, Noção de diferença. A perspectiva pósmoderna esteve presente em grande parte dos artigos que tratavam do tema. Com relação ao embasamento teórico, Stuart Hall (2006) foi o autor mais citado. 0 autor sugere que na contemporaneidade as identidades são fragmentadas e não fixas, o indivíduo pode desenvolver diferentes aspectos do seu self $(\mathrm{eu})$ ao longo da vida.

Percebeu-se também que a relação pessoaobjeto era muito utilizada, principalmente o conceito do self estendido (Belk, 1988). Até hoje a ideia de que os objetos são centrais para a definição do self dos consumidores ainda é presente em alguns trabalhos. Paralelamente a esse entendimento, identificou-se o conceito dos significados dos bens para a construção da identidade. Segundo McCracken (2003), os consumidores utilizam os significados mercadológicos dos bens de consumo para construir suas noções de si.

No entanto, outros conceitos também se inserem para investigar as questões relacionadas a esse domínio e suas margens. É o caso, por exemplo, da identidade de grupo. Esse conceito pode ser utilizado para problemáticas sobre consumo experiencial, identidade coletiva, comunidades de consumidores, entre outras. A principal ideia por trás é que o valor simbólico trazido pelo consumo é compreendido pelos membros de um grupo de pessoas.

Por fim, foi encontrado em dois artigos do corpus desta pesquisa o conceito de noção de identidade. Woodward (2009) afirma que a identidade é uma questão relacional, o que define o que somos também está em algo além do nosso ser; o que não somos também nos define.
Tendo em vista os cinco principais conceitos analisados, compreendemos que os artigos dessa revisão possuem um enfoque teórico diverso, no entanto, ainda se concentram, em maior parte, nas publicações seminais sobre o tema, ainda anteriores à publicação de Arnould e Thompson em 2005, como é o caso do conceito de extensão do self de Belk (1988) e significados dos bens de McCracken (2003). Dessa forma, questiona-se qual seria então o futuro dos trabalhos que abordam essa temática no campo da CCT? Assim como apresentar uma compreensão do que fora estudado acerca desse tema dentro da CCT, tentou-se, nesta pesquisa, ir além do objetivo apresentado e buscar identificar algumas possíveis inspirações para futuras pesquisas.

Arnould e Thompson (2015) discutiram quatro eixos teóricos que sobrepõem as possíveis temáticas de estudo da CCT: cultura como rede distribuída, políticas de consumo, abordagens teóricas culturais do marketing e teorias culturais regionais. Em outras palavras, nos anos seguintes ao artigo de 2005, a estrutura discursiva da CCT foi transformada pela infusão de novos vernáculos teóricos. Por exemplo, para analisar a cultura como rede distributiva, vem se fazendo o uso da Assemblege Theory, cuja concepção aborda conceitos da teoria ator rede (Latour, 2005) e Teoria da Prática (Warde, 2005). Através dos conceitos de subculturas de consumo, tribos de consumo, comunidades de consumo, e as microculturas de consumo, os pesquisadores do CCT articularam um entendimento de cultura do consumo como uma rede de fragmentação, embora muitas vezes interligada, subsistemas que fornecem aos consumidores uma gama diversificada de recursos para a construção da identidade.

Apoiando-se na inserção desses novos aportes teóricos, sugere-se para estudos futuros que os trabalhos envolvendo a Identidade do Consumidor comecem a questionar como os consumidores co-criam juntos os recursos fornecidos pelo mercado, ao invés de serem vistos apenas como receptores dos mesmos.

No que tange às limitações, acredita-se que a principal apresentada é a metodológica, uma vez que o método escolhido, apesar de dar embasamento teórico para fornecer um amplo debate sobre a temática, foi delimitado por escolhas dos autores para que se pudesse 
analisar com maior profundidade o domínio Projetos de Identidade do Consumidor. Para além desta limitação, as escolhas feitas foram justificadas metodologicamente e se mostraram necessárias para uma melhor compreensão do domínio escolhido.

Acredita-se que esse estudo traz contribuições importantes para área de comportamento do consumidor, principalmente seguindo o eixo de cultura e consumo, podendo ser compreendido como um guia para futuros trabalhos sobre identidade do consumidor, além de uma forma de refletir sobre novos conceitos e até teorias sobre o tema.

\section{REFERÊNCIAS}

Ahuvia, A. C. (2005). Beyond The Extended Self: Loved Objects and Consumers' Identity Narratives. Journal of Consumer Research, 32(1), 171-184.

Arnould, E. J., \& Thompson, C. J. (2005). Consumer Culture Theory (CCT): Twenty Years of Research. Journal of Consumer Research, 31(4), 868-882.

Arnould, E., \& Thompson, C. (2007). Consumer Culture Theory (And We Really Mean Theoretics. In: Consumer Culture Theory. Emerald Group Publishing Limited. p. 3-22.

Arnould, E J., \& Thompson, C J. (2015). Introduction: Consumer Culture Theory: Ten Years Gone (And Beyond). In: Consumer Culture Theory. Emerald Group Publishing Limited. p. 1-21.

Bahl, S., \& Milne, G. R. (2009). Talking to Ourselves: A Dialogical Exploration of Consumption Experiences. Journal of Consumer Research, 37(1), 176-195.

Barbosa, M. A. (2010). Pós-Modernidade: A Identidade-Real Ou Virtual? Direitos Culturais, 5(8), 75-92.

Barboza, R. A., \& Silva, R. R. (2013). Subcultura Cosplay: a extensão do Self em um grupo de consumo. Revista Brasileira de Marketing, 12(2), 180-202.

Baudrillard, J. (2007). A Sociedade de Consumo. Rio De Janeiro: Edições 70.

Baumann, Z. (2003). Comunidade: A Busca Por Segurança No Mundo Atual. Rio De Janeiro: Jorge Zahar Ed.

Belk, R. W. (2013). Extended Self In A Digital World. Journal of Consumer Research, 40(3), 477-500.

Belk, R. W. (1988). Possessions and the Extended Self. Journal of Consumer Research, 15(2), 139168.

Belk, R. W., Ger, G., \& Askegaard, S. (2003). The Fire of Desire: A Multisited Inquiry Into Consumer
Passion. Journal of Consumer Research, 30(3), 326-351.

Birdwell, A. E. (1968). A Study of the Influence of Image Congruence on Consumer Choice. The Journal of Business, 41(1), 76-88.

Canniford, R., \& Shankar, A. (2012). Purifying Practices: How Consumers Assemble Romantic Experiences of Nature. Journal of Consumer Research, 39(5), 1051-1069.

Casotti, L. M., \& Suarez, M. C. (2016). Dez Anos De Consumer Culture Theory: Delimitações e Aberturas. Revista de Administração de Empresas, 56(3), 353-359.

Chen, W., \& Nelson, M. R. (2017). Champagne Taste, Beer Budget: The New Poor's Incongruent Capital and Consumption. Journal of Consumer Culture.

Cova, B. (1997). Community and consumption: towards a definition of the linking value of products or services. European Journal of Marketing, 31(3/4), 297-316.

Cova, B., Kozinets, R., \& Shankar, A. (2012). Seeking Community Through Battle: Understanding The Meaning of Consumption Processes for Warhammer Gamers' Communities Across Borders. In: Consumer Tribes. Routledge. p. 223-234.

Cronin, J. M., McCarthy, M. B., \& Collins, A. M. (2014). Covert Distinction: How Hipsters Practice Food-Based Resistance Strategies in The Production of Identity. Consumption Markets \& Culture, 17(1), 2-28.

Epp, A. M., \& Price, L. L. (2009). The Storied Life of Singularized Objects: Forces of Agency and Network Transformation. Journal of Consumer Research, 36(5), 820-837.

Gaião, B. F. S., Souza, I. L., \& Leão, A. L. M. S. (2012). Consumer Culture Theory (CCT) já é uma Escola de Pensamento em Marketing? Revista de Administração de Empresas, 52(3), 330344.

Goulding, C., \& Saren, M. (2009). Performing Identity: An Analysis of Gender Expressions at The Whitby Goth Festival. Consumption, Markets and Culture, 12(1), 27-46.

Grubb, E. L., \& Grathwohl, H. L. (1967). Consumer Self-Concept, Symbolism and Market Behavior: A Theoretical Approach. Journal of Marketing, 31(4), 22-27.

Hall, S. (2006). A Identidade Cultural na PósModernidade. 11. Ed. Rio De Janeiro: Dp\&A.

Helal, D. H., Piedade, A. F., \& Dias, N. A. (2008). 0 perfil da força de trabalho nas regiões metropolitanas do Brasil: alterações e implicações. Revista Gestão \& Tecnologia, 8(2), 1-19.

Holbrook, M. B., \& Hirschman, E. C. (1982). The Experiential Aspects of Consumption: 
Consumer Fantasies, Feelings, And Fun. Journal of Consumer Research, 9(2), 132-140.

Holt, D. B. (2002). Why Do Brands Cause Trouble? A Dialectical Theory of Consumer Culture and Branding. Journal of Consumer Research, 29(1), 70-90.

Joy, A., \& Sherry Jr, J. F. (2003). Speaking of Art as Embodied Imagination: A Multisensory Approach to Understanding Aesthetic Experience. Journal of Consumer Research, $30(2), 259-282$.

Kates, S. M. (2002). The Protean Quality of Subcultural Consumption: An Ethnographic Account of Gay Consumers. Journal of Consumer Research, 29(3), 383-399.

Kozinets, R. V. (2002). Can Consumers Escape the Market? Emancipatory Illuminations from Burning Man. Journal of Consumer Research, 29(1), 20-38.

Jafari, A., \& Goulding, C. (2008). We Are Not Terrorists!" Uk-Based Iranians, Consumption Practices and The "Torn Self. Consumption, Markets and Culture, 11(2), 73-91.

Latour, B. (2005). Reassembling the Social: An Introduction to Actor-Network-Theory. Oxford University Press.

Levy, S. J. (1959). Symbols for Sale. Harvard Business Review, 37, 117-124.

McCracken, G. (2003). Cultura e Consumo: Novas Abordagens ao Caráter Simbólico dos bens $e$ das atividades de consumo. Rio De Janeiro: Mauad.

Macias-Chapula, C. A. (1998). The Role of Informetrics and Scientometrics in the National and International Perspective. Ciência da Informação, 27(2).

Markus, H., \& Nurius, P. (1986). Possible Selves. American Psychologist, 41(9), 954.

Miller, D. (2007). Consumo Como Cultura Material. Horizontes Antropológicos, 13(28), 33-63.

Morgan, A. J. (1993). The Evolving Self in Consumer Behaviour: Exploring Possible Selves. ACR North American Advances.

Patterson, M., \& J. Schroeder (2013). Borderlines: Skin, Tattoos and Consumer Culture Theory. reprinted in M. Tadajewski and R. Cluley (eds.). International Perspectives on Marketing Theory, London: Sage, Volume 4: Transforming Marketing, Consumer and Society Dynamics, Sage: London, 3-20.

Pimentel, A. (2001). O Método da Análise Documental: Seu uso numa Pesquisa Historiográfica. Cadernos de Pesquisa, 114, 179-195.
Price, L. L., Arnould, E. J., \& Curasi, C. F. (2000). Older Consumers' Disposition of Special Possessions. Journal of Consumer Research, 27(2), 179-201.

Rocha, E., \& Barros, C. (2004). Dimensões Culturais do Marketing: Teoria Antropológica, Estudos Etnográficos e Comportamento do Consumidor. Anais do 28ㅇ Enanpad.

Schouten, J. W. (1991). Selves in Transition: Symbolic Consumption in Personal Rites of Passage and Identity Reconstruction. Journal of Consumer Research, 17(4), 412-425.

Silva, T. T. (2009). A Produção Social da Identidade e da Diferença. In: Silva, T. T. (org.); Hall, S.; Woodward, K. Identidade e Diferença: A perspectiva dos Estudos Culturais. 9.ed. Petrópolis, RJ: Vozes, 73-102.

Smith, S., Fisher, D., \& Cole, S. J. (2007). The Lived Meanings of Fanaticism: understanding the complex role of labels and categories in defining the self in consumer culture. Consumption Markets \& Culture, 10(2), 77-94.

Thompson, C. J., Arnould, E., \& Giesler, M. (2013). Discursivity, Difference, and Disruption: Genealogical Reflections on the Consumer Culture Theory Heteroglossia. Marketing Theory, 13(2), 149-174.

Tian, K., \& Belk, R. W. (2005). Extended Self and Possessions in the Workplace. Journal of Consumer Research, 32(2), 297-310.

Tumbat, G., \& Belk, R. W. (2010). Marketplace Tensions in Extraordinary Experiences. Journal of Consumer Research, 38(1), 42-61.

Üstüner, T., \& Holt, D. B. (2007). Dominated Consumer Acculturation: The Social Construction of Poor Migrant Women's Consumer Identity Projects in a Turkish Squatter. Journal of Consumer Research, 34(1), 41-56.

Venkatesh, A. (2010). The Aesthetics of Luxury Fashion, Body and Identify Formation. Journal of Consumer Psychology, 20, (4), 459-470.

Warde, A. (2005). Consumption and Theories of Practice. Journal of Consumer Culture, 5(2), 131-153.

Weijo, H A., Martin, D. M., \& Arnould, E. J. (2018). Consumer Movements and Collective Creativity: The Case of Restaurant Day. Journal of Consumer Research, 45(2), 251-274.

Woodward, K. (2000). Identidade e Diferença: Uma Introdução Teórica e Conceitual. Identidade e Diferença: A Perspectiva dos Estudos Culturais. Petrópolis: Vozes, p. 7-72. 
Compreendendo o Domínio "Projetos de Identidade do Consumidor": Revisão de literatura considerando a produção científica brasileira

Understanding the "Consumer Identity Projects" domain: A literature review considering the Brazilian scientific production

\begin{abstract}
The consumer Culture Theory refers to a set of theoretical perspectives that share the same sociocultural orientation about the dynamic relationships between consumer, market and cultural meanings. Considering this, in 2005, Arnould and Thompson proposed a framework with four thematic domains of CCT that are interrelated. The objective of this article was to provide a conceptual overview of the works that have as central theme the domain "Consumer identity projects". To this end, a literature review was conducted on the subject considering the Brazilian scientific production from 2005 to 2018. It was perceived that the Brazilian authors used the person-object relationship, especially the concept of the extended self for Belk, in addition to postmodern perspectives on fragmented identities for Hall. Therefore, we consider that the discursive structure of the articles remained in the theories and concepts about initial identity still disseminated by the publication of 2005, failing to reach other more recent proposals.
\end{abstract}

Keywords: Identity, Consumer Culture Theory, Consumption. 